\title{
Comparison of lime powder and caustic soda as a pre-treatment for ammonia-nitrogen removal from a scheduled waste leachate
}

\begin{abstract}
Studies on leachate taken from scheduled waste landfill are limited. This might be due to the complex characteristics of the leachate from scheduled waste landfill compared to other types of landfills. Leachate is known as a strong wastewater in terms of its organic matter and ammonia content. In this study, a pre-treatment on the removal of ammonia-nitrogen (NH3N) by coagulation on a leachate sample taken from a Scheduled Waste Landfill (SWL) is reported. The coagulation was performed using lime $(\mathrm{Ca}(\mathrm{OH}) 2)$, and caustic soda $(\mathrm{NaOH})$ with varying $\mathrm{pH}$ and amount of coagulant. A different dosage of $\mathrm{Ca}(\mathrm{OH}) 2$, and $\mathrm{NaOH}$ was applied and the removal efficiency using both coagulants were investigated to find the most optimum dosage for NH3-N removal. Results showed that the percentage of NH3-N removal was relatively the same for both $\mathrm{Ca}(\mathrm{OH}) 2$ and $\mathrm{NaOH}$ which was up to $45 \%$ and $48 \%$, respectively. The optimum $\mathrm{pH}$ and dosage of coagulant for the removal process using $\mathrm{Ca}$ $(\mathrm{OH}) 2$ was $\mathrm{pH}=12.40 \pm 0.02$ and $6 \mathrm{gLi} 1$, respectively while with $\mathrm{NaOH}$ was $\mathrm{pH}=12.83 \pm 0.02$ and $8 \mathrm{gLi} 1$, respectively. A small difference in the removal of $\mathrm{NH} 3-\mathrm{N}$ with a less dosage of coagulant used in the study suggests that lime $(\mathrm{Ca}(\mathrm{OH}) 2)$, is a better choice for the pretreatment process.
\end{abstract}

Keyword: Ammonia-nitrogen; Caustic soda; Leachate; Lime; Scheduled waste 